\title{
INDÍGENAS ANDINOS EN CHILE COLONIAL: INMIGRACIÓN, INSERCIÓN ESPACIAL, INTEGRACIÓN ECONÓMICA Y MOVILIDAD SOCIAL (SANTIAGO, SIGLOS XVI-XVII)*
}

POR

JAIME VALENZUELA MÁRQUEZ

Pontificia Universidad Católica de Chile. Instituto de Historia

Desde las expediciones de conquista del siglo XVI llegaron a Chile numerosos indigenas andinos que sirvieron a los españoles, se asentaron y se integraron en los espacios laborales $y$ sociales de este "nuevo mundo» periférico; formaron redes y parentescos locales, tuvieron descendencia, varios se transformaron en artesanos y algunos dictaron testamentos o dejaron huellas en documentos eclesiásticos y notariales que nos permiten observar su movilidad e inserción local.

Este trabajo aporta antecedentes y desvela los principales ejes de un proceso que aparece como medular para entender la formación de la sociedad colonial chilena temprana y, a la vez, para dar cuenta de fenómenos de circulación, desarraigo y asentamiento de población indígena en el virreinato peruano meridional.

Palabras Clave: Indigenas, inmigración, Chile, Perú, artesanos, siglos XVI-XVII.

\section{PRESENTACIÓN DEL PROBLEMA E HIPÓTESIS DE TRABAJO}

El objetivo de este artículo es estudiar, en un contexto colonial temprano, la inserción espacial, social y económica que vivió un grupo importante de in-

* Este artículo forma parte del proyecto de investigación: «Inmigrantes indígenas. Indios cuzcos y huarpes en Chile colonial (siglos XVI-XVII)», financiado por FONDECYT (n. ${ }^{\circ}$ 1070451). Agradecemos la colaboración de Hugo Contreras y Patricia Palma, así como los comentarios y sugerencias de Juan Carlos Estenssoro. 
dígenas originarios de los Andes y de otras regiones costeras peruano-quiteñas que hicieron un derrotero migratorio hacia Chile central ${ }^{1}$.

En particular, nos interesa concentrarnos en la ciudad de Santiago y su entorno suburbano; espacio que, si bien periférico y modesto en el contexto virreinal, constituyó un escenario representativo de la diversidad socioétnica que caracterizaba al mundo urbano colonial, donde los indígenas locales y forasteros convivían cotidianamente con personas de diferentes orígenes, colores y estatus.

En efecto, si bien las migraciones inter e intrarregionales eran un fenómeno común en América prehispánica, con la llegada de los europeos éstas comenzaron a desarrollarse a escalas geográficas más amplias, enmarcadas por la dinámica de las expediciones de conquista que circularon por el continente y por las compulsiones laborales o estrategias coloniales que llevaron a la «desnaturalización» de numerosos grupos humanos, con consecuencias sociales y étnicas de dimensiones hasta entonces desconocidas. De esta manera, podemos encontrar, por ejemplo, a indios de Nicaragua en la conquista del Perú o un traslado masivo de población nahuatl para «colonizar» y «civilizar» el espacio chichimeca de la frontera norte de México, luego de descubrirse sus riquezas argentíferas. A la actual Colombia también llegaron indígenas de México y sobre todo de Panamá, que fueron la base para la conquista de Ecuador, mientras que, en sentido inverso, se apreció un intenso movimiento de indios del Cuzco y del actual Ecuador hacia Colombia, conducidos por el conquistador Sebastián de Benalcázar; flujo migratorio que no se interrumpió y que alimentó luego la conformación social de la propia ciudad de Santafé2. En Lima, por su parte, un censo elaborado en 1613 revelaba que más del $90 \%$ de los indígenas eran forasteros y hacia el final del siglo aún tenían esta condición cerca de la mitad de los trabajadores indígenas de la ciudad ${ }^{3}$. En el siglo XVII también veremos las «desnaturalizaciones» forzadas de huarpes cuyanos o de indígenas «rebeldes», como los calchaquíes tucumanos y los mapuches araucanos.

La ciudad de Santiago de Chile se constituyó en un temprano polo de atracción de personas provenientes de distintos orígenes geográficos y étnicos.

1 Es necesario aclarar que al hablar de «los Andes», «espacio andino» o «indígenas andinos» estaremos haciendo referencia a las regiones vinculadas al virreinato peruano que hoy conforman los países de Perú, Bolivia y Ecuador.

2 Rodríguez Jiménez, 2002: 16. También, Mellafe, 1986: 131-145. Borah y Cook, 1978: 383-398. Castro Gutiérrez, 1998: 419-440. Sánchez Albornoz, 2003. Vieira Powers, 1995. Wightman, 1990.

3 Cook, 13-14 (Paris, 1976): 33-50. Charney, 2000: 139-156. Robinson (ed.), 1990. 
Por cierto, como veremos, este fenómeno ya se experimentaba con anterioridad, desde la llegada del imperio inca y el establecimiento del límite sur del Tawantinsuyu. Sin embargo, será la conquista hispana y el despliegue del sistema colonial - con su estructura imperial, coerción demográfica y laboral, y estructura político-religiosa - quienes darán el escenario apropiado para la emergencia de procesos migratorios nuevos.

Con respecto a aquella diversidad socioétnica de Santiago no está de más indicar que ésta se daba ya en el propio universo de los españoles — marcados por las variantes regionales y los roces interculturales de su origen peninsular - aunque era más evidente y masiva en la mayoría demográfica no hispana, configurada por indígenas del valle central, mapuches de la Araucanía, veliches - huilliches - de Osorno y Chiloé continental, cuncos de esta última isla, cuzcos de los Andes, huarpes de la región transandina de Cuyo o juríes del Tucumán, además de «morenos» bozales y ladinos, y la amplia gama de mestizos que nacieron de sus uniones ${ }^{4}$.

Desde temprano, también, se comenzaron a formar redes de intereses, de familia o de amistad entre los distintos actores, lo que constituyó un proceso central en la configuración de las dinámicas interétnicas 5 . También se desarrollaron estrategias y espacios de integración formal al sistema colonial, tanto en el plano laboral - actividad artesanal, comercio y pequeña agriculturacomo en el plano asociativo — cofradías y gremios 6 - y jurídico — uso de la justicia colonial para zanjar conflictos, acceso a la propiedad inmobiliaria, utilización de los mecanismos occidentales de herencia y de transacción-, por mencionar algunos. En relación a esto último, vale la pena destacar la existencia de numerosos testamentos de indígenas, así como contratos notariales - especialmente asientos de trabajo - que han constituido una base documental muy importante para dar cuenta de nuestras hipótesis de trabajo. Se trata de un corpus de información que permite relevar no sólo los deseos postreros o las vinculaciones laborales de los sujetos, sino también sus oficios, matrimonios, propiedades y vinculaciones urbanas, tipo de explotación de sus solares, configuración de redes sociales, mestizajes, movilidad social e, incluso, genealogías 7 .

4 De Ramón, 4 (Santiago, 1965a): 191-228; 12 (Santiago, 1974-1975): 93-373; 13 (Santiago, 1976): 97-270; 1992. Zúñiga, 2002. Valenzuela Márquez, 1999: 139-163; 2005: 71-93.

5 Poloni Simard, 2000.

6 Valenzuela Márquez, 43 (Santiago, 2010a).

7 Sobre el papel del testamento indígena en el contexto de la sociedad colonial urbana, en la construcción de redes sociales, herencias materiales y economías espirituales, Poloni Simard, 1997b: 279-299. Kellogg y Restall, 1998. 
Todas estas huellas documentales, si bien son generalmente fragmentarias e indiciarias, permiten generar una serie de hipótesis en torno al proceso que vivieron los forasteros que concentran nuestra atención. Podemos pensar, así, que estamos en presencia de sujetos marcados por una experiencia de desarraigo. Situación vinculada, en primer lugar, a la condición de inmigrante propiamente tal, que supone el alejamiento - generalmente definitivo- de su espacio geográfico de origen, así como el desplazamiento y, luego, el proceso de asentamiento e inserción en el lugar de destino. En segundo lugar, al menos para aquellos que no vinieron en los traslados masivos de las expediciones conquistadoras, la individualidad con la que vivieron este proceso, que implicó, a su vez, un quiebre personal con la comunidad de origen y la eventual pérdida de lazos sociales y culturales con sus miembros. En tercer lugar, el cambio fundamental que conllevó dejar el espacio rural y aldeano, y asentarse en la complejidad de una ciudad, independientemente de si ésta era más bien modesta en sus pretensiones urbanas, como Santiago de Chile. Para estas dos últimas constataciones, sin embargo, debemos considerar la hipótesis alternativa de que pudiera tratarse de sujetos con una migracion intermedia antes de su viaje a Chile, ya insertos en una dinámica de movilidad y de inserción urbana previa en el contexto andino - como lo demostrarían, por ejemplo, sus conocimientos artesanales - y, por lo tanto, distantes del mismo nivel de desarraigo traumático que podrían haber tenido los inmigrantes forzados de la primera época. Para unos y otros, sin embargo, independientemente de su grado de desarraigo y ladinización previa, se hace evidente la necesidad vital de «rearraigarse», de construir nuevos lazos sociales y nuevas redes materiales en el lugar de asentamiento. Proceso tanto más claro en el caso de sus descendientes, que transportaron una «memoria familiar foránea» y, al mismo tiempo, una «experiencia personal local».

La inmigración, la inserción en un contexto urbano definido por reglas del sistema colonial español, la integración económica y la interacción profunda y cotidiana con «otros» permitirán la emergencia de nuevos tejidos comunitarios, así como de nuevas identidades sociales y culturales, como hemos dicho con anterioridad.

Nuestro trabajo pretende mostrar los ejes de este proceso, centrándose en un actor específico: los inmigrantes indígenas provenientes del espacio andino, que comienzan a llegar a Santiago desde muy temprano en el siglo XVI. 


\section{GENEALOGÍA DE UN PROCESO}

La presencia andina en Chile central tiene antecedentes que se vinculan con la fase expansiva del Tawantinsuyu hacia el sur, cuando algunas colonias de mitimaes llegaron a asentarse en las riberas del río Mapocho - futuro enclave de la ciudad de Santiago - con el fin de proteger la frontera meridional del imperio inca ante la hostilidad de los aucaes que habitaban más al sur ${ }^{8}$. De hecho, la lengua quechua era de uso común en la región; tanto así que, gracias a los intérpretes que lo acompañaban desde el Cuzco, el conquistador Pedro de Valdivia no habría tenido problema para comunicarse con los caciques locales ${ }^{9}$. Ello hace pensar que los yanaconas andinos que acompañaron la expedición hispana, en 1540, no habrían llegado a un espacio cultural completamente ajeno. Estamos hablando de un contingente de alrededor de mil personas - entre hombres, mujeres y niños-, muchos de los cuales venían acompañando a sus mallku de Charcas, donde, por lo demás, se encontraban las tierras y los indios que le habían sido otorgados a Valdivia por Pizarro y donde los españoles aprovecharon la capacidad de movilizar población que había demostrado la confederación qaraqara-charka durante el dominio inca ${ }^{10}$.

Lo cierto es que como cargadores, traductores, sirvientes, «soldados», mineros y concubinas, estos involuntarios migrantes fueron activos ayudantes de los invasores europeos. Y si bien la coerción laboral sentó las bases iniciales de la relación entre andinos e hispanos en Chile, su rápida acomodación a las obligaciones impuestas por los conquistadores ayudaron a que tanto los indígenas locales como los propios españoles tendieran a verlos y a tratarlos como verdaderos «colaboradores» de la empresa. Por lo demás, su labor fue central desde un comienzo, extrayendo oro y trabajando los sembrados - cuando la encomienda de autóctonos aún se encontraba en su fase

8 El vocablo quechua auca servía para designar a pueblos o animales «salvajes», y los incas lo habían utilizado para denominar lo que entendían como el carácter traicionero y hostil de los habitantes del centro-sur chileno: Silva, 6 (Santiago, 1986): 7-16. León, 10 (Arica, 1983): 95-115. Cornejo, 2001: 75-129. Pärssinen, 2003. Sternfeld, 2007. Sobre la movilidad y distancias geográficas asociadas al traslado de mitimaes en el Tawantinsuyu, ver Murra, 2002 [1975]: 85-125. Lorandi y Rodríguez, 2003: 129-170.

9 Caciques que, por cierto, formaban parte de la estructura andina, toda vez que Quilacanta representaba la autoridad imperial a nivel local y Vitacura era jefe de un grupo de aquellos mitimaes, siendo ambos de origen cuzqueño: Silva, 16 (La Serena, 1977-1978): 223. Barros Arana, 1999 [1884], vol. I: 178.

10 Carta de Pedro de Valdivia a Hernando Pizarro (La Serena, 4 de septiembre de 1545), Valdivia, 1991: 83. Platt, Bouysse-Cassagne y Harris, 2006: 848-849, 886, 891, 898, 929, 1002 y 1008. El vocablo aymara mallku designaba a los jefes de señoríos. 
embrionaria - o auxiliando a los hispanos en las refriegas contra los picunches del valle central ${ }^{11}$.

A fines del siglo XVI y comienzos del siguiente ya se había consolidado la presencia de estos forasteros en el seno de la sociedad colonial, formando un sector que alcanzaría a cerca del $9 \%$ de la población indígena de la ciudad ${ }^{12}$; proporción no menos significativa si consideramos la influencia cualitativa que tendrán en las dinámicas sociales y laborales que veremos más adelante.

Por otra parte, se trata de un sector poblacional que, más allá de su adscripción global al área andina, contiene una complejidad y diversidad que se hacen patentes al observar las procedencias individuales, al menos de aquellos inmigrantes para los cuales poseemos información. En efecto, en los testamentos que varios de ellos dictaron algunas décadas más tarde, así como en los numerosos asientos de trabajo y documentos conservados en los archivos notariales, observamos un origen geográfico bastante más variado que el de los acompañantes de los conquistadores citados, encontrando personas procedentes de lugares tan disímiles como Arequipa, Cuzco, Trujillo, Lima, Jauja (Junín), Huamanga (Ayacucho), Huánuco y Pisco; también vemos a indígenas procedentes de Chuquisaca y Cochabamba (al sur de la actual Bolivia) e incluso de Guayaquil, Quito y Puerto Viejo (Manabí, Ecuador).

La hipótesis de dos corrientes migratorias diferentes podría explicar, pensamos, la dispersión relativa de su origen específico, si consideramos que luego de aquella primera corriente masiva de mediados del siglo XVI se habría dado un movimiento más individual y diversificado. Movimiento alimentado, probablemente, con numerosos «trajinantes» indígenas, desarraigados por la dinámica devastadora de la conquista y, luego, agobiados por las compulsiones laborales del mundo colonial que los impulsaba a huir lejos de sus encomenderos ${ }^{13}$.

11 Silva, 1990: 22. Villalobos, 1983, vol. II: 83. León, 14 (Arica, 1985): 91-114. El propio Valdivia, dando cuenta de la ayuda prestada por estos indígenas, llegó a decir que «los tenemos por hermanos, por haberlos hallado en nuestras necesidades por tales». En otra carta confirmaba la deuda contraída, así como la cercanía y confianza alcanzada entre los hispanos y los andinos, cuando señalaba que a los yanaconas «los hemos ya por hijos»: Carta de Pedro de Valdivia al emperador Carlos V (La Serena, 4 de septiembre de 1545); Carta de Pedro de Valdivia a Hernando Pizarro (La Serena, 4 de septiembre de 1545); Instrucción de Pedro de Valdivia a sus apoderados en la Corte (Concepción, 15 de octubre de 1550), Valdivia, 1991: 73-74, 83 y 146, respectivamente.

12 Porcentaje basado en el estudio de Álvaro Jara y en el informe elaborado en 1614 por el licenciado Hernando Machado: Jara, 1987 [1959]: 59-63. El informe de Machado lo recoge Vázquez de Espinosa, 1969 [ca. 1629]: 45.

${ }^{13}$ El D $\mathrm{r}$ D. Nicolás Polanco de Santillana propone a Vra Mag ${ }^{\mathrm{d}}$ como los indios cuscos y juries que se an ido al Reyno de Chile por fugitivos gozan de la libertad de no tributar, que se 
Otra hipótesis es que buena parte de estos andinos sí hayan estado dentro de aquella inmigración «originaria», siendo muy niños y acompañando a sus padres, lo cual podría ser válido para los testimonios anteriores al cambio de siglo - considerando un máximo de sesenta años desde la llegada de Valdivia-. Es lo que podemos apreciar en el caso del «cuzco» Gaspar, que en un juicio por tierras de 1604 declaraba en quechua «haver benido a este rreyno de los del peru entre los demas yndios del cusco que binieron en serbisio del dicho governador don Pedro de valdibia»; el documento apuntaba que «por su aspecto paresçio ser de sesenta años» ${ }^{14}$.

De ser cierta la conjetura anterior, la diversidad regional de los inmigrantes podría explicarse por su desplazamiento previo al Cuzco, desde donde se habrían incorporado a la expedición de Valdivia; esto, pues dentro de aquellos que dejaron testimonio documental en Chile, no se aprecia una eventual relación con la zona Cuzco-Collao que habría alimentado preferentemente a la hueste hispana. Esta circulación migratoria escalonada puede ejemplificarse en el caso del zapatero - probablemente mestizo - Hernando Muñoz, nacido en Huánuco, pero que al testar en Santiago (1614), declaraba tener un hijo de unos veinte años nacido en Lima y que su padre residía también en dicha ciudad, la que habría sido, entonces, el «escalón intermedio» antes de su emigración a Chile ${ }^{15}$.

Ahora bien, frente a esta variedad de orígenes y circuitos, y ante la necesidad y posibilidad de arraigo e integración en el «nuevo mundo» santiaguino, los propios andinos generarán una suerte de adscripción cultural y geográfica unívoca, identificándose con la antigua capital inca. En efecto, ya desde muy temprano la mayoría comienza a denominarse - y a ser denominados- como cuzcos, asumiendo el topónimo de la ciudad inca como una suerte de «etnónimo» — o gentilicio - que les otorgaba una identidad socioétnica para posicionarse en el contexto chileno. Referente que, adoptado también por la taxonomía colonial, llegaría a generalizarse entre los distintos individuos provenientes del espacio andino independientemente de su origen geográfico específico y con un uso que también veremos prolongarse en sus descendientes «criollos». De esta forma, la denominación cuzco que encontramos con frecuencia

haga con ellos lo que con los yanaconas, Santiago, 28 de mayo de 1652, Archivo General de Indias (AGI), Chile, vol. 12, leg. 5, n. ${ }^{\circ} 74$.

14 El capitán Juan Ortiz de Araya contra el capitán Antonio Méndez, por las tierras de Lampa, Santiago, 11 de mayo de 1604, Archivo Nacional Histórico, Real Audiencia (ANH.RA), vol. 1978, fj. 134v.

15 Testamento de Hernando Muñoz, 16 de diciembre de 1614, Archivo Nacional Histórico, Escribanos de Santiago (ANH.ES), vol. 82, fjs. 488- 490. 
en las fuentes para referirse a los forasteros andinos no comprendía sólo a los nacidos en el Cuzco o en su región próxima, ni se limitaba a las generaciones asociadas a la conquista, pues muchos de los indígenas que siguieron llegando a Chile en las etapas posteriores adoptarán tal calificativo para definir su posición sociocultural ${ }^{16}$.

Esta autodenominación quizás se alimentaba del eco «ennoblecedor» que evocaba supuestos privilegios a los que habrían sido acreedores los yanaconas cuzqueños de los conquistadores por la colaboración prestada en aquella etapa crucial. Quizás, también, porque el topónimo se ligaba al linaje inca ${ }^{17}$. Lo cierto es que en 1615 los mayordomos y procuradores de la cofradía mercedaria de la Guadalupe, «nombrada de la adbocaçion de los yndios naturales y desendientes de cuzcos», daban poder al provincial de la orden, que partía a Europa, para que pidiese la confirmación de su fundación y para solicitar la concesión de privilegios a los que supuestamente tendrían derecho por el papel jugado en la conquista:

[...] y asymismo para que ante su magestad en Rey don phelipe nuestro señor y su rreal consejo pidan se nos agan merçedes y los prebilexios que ffuere seruido atendiendo que somos sus leales basallos naturales del piru y hijos los mas de los hermanos de la dicha coffradia de padres cuzcos y de los que entraron a la conquista deste Reino y le sirbieron en el como es notorio y en espeçial pida sseamos puestos en los actos puvlicos con las ynsignias de la dicha nuestra coffradia en lugares honrrosos Prefiriendo a los negros y mulatos que nos lo an pretendido ympedir y tambien a los naturales desta tierra pues no an sido tan fieles como nosottros ${ }^{18}$.

Por lo demás, la colaboración prestada en los primeros tiempos no sólo se tradujo en las palabras de agradecimiento paternalista de los conquistadores, sino que también se concretó en el otorgamiento de solares por parte del Cabildo de Santiago, en la riba extraurbana del río Mapocho, donde se fueron instalando los antiguos yanaconas que ahora comenzaban su proceso de transformación en moradores urbanos.

En esta misma línea de inserción espacial e identidad «étnica», las pervivencias y los usos lingüísticos constituyen una vía particularmente interesante para constatar la presencia e importancia del mundo indígena andino en Chile colonial. También aparece como una evidencia singular de la multiculturalidad que se vivía en espacios de concentración demográfica y plural como la

16 Este tema se analiza con mayor profundidad en Valenzuela Márquez, 2010b.

17 Cf. Ruiz Rodríguez, 2000: 248-249. Estenssoro Fuchs, 2005.

18 Poder de los mayordomos y de los procuradores de la cofradía de Nuestra Señora de Guadalupe a fray Juan de la Barrera, provincial de la orden de Nuestra Señora de la Merced, Santiago de Chile, 11 de abril de 1615, ANH.ES, vol. 53, fjs. 191-191v. 
ciudad de Santiago. En efecto, el uso y extensión de la lengua «general» quechua es mencionado frecuentemente en los documentos de la época para la capital chilena y su entorno, como lo refleja, por ejemplo, la carta que en 1580 escribía el obispo de Santiago, destacando la labor del sacerdote Juan Blas, que «sabe muy bien la lengua de la tierra [—es decir, el mapudungun- - y la del Pirú» ${ }^{19}$.

El documento anterior guía al investigador hacia los lugares donde se concentraba la tarea pastoral de éste y de otros agentes coloniales quechuaparlantes de la capital, coincidiendo con otro tipo de documentos en aquel extramuro al norte de la urbe que fue denominado con el vocablo quechua de chimba ${ }^{20}$. Así, al destacar las actividades del sacerdote Gabriel de Villagra, el obispo señalaba que éste se encontraba «ocupado en la doctrina de la otra parte de las chácaras de esta ciudad», ligando inmediatamente esta labor con el hecho de que era «buena lengua, ansí de la tierra como de la del Pirú»» ${ }^{21}$.

Rolando Mellafe, por su parte, subraya las lenguas predominantes en la Chimba: quechua, allentiac — hablada por los huarpes originarios de San Juan-y mapuche, además de los dialectos africanos hablados por los inmigrantes negros que allí se radicaron, demostrando con ello el espacio pluriétnico que se estaba conformando en ese sector suburbano ${ }^{22}$.

\section{LA CHIMBA}

Más allá del límite propiamente urbano de Santiago, definido por el río Mapocho, se encontraba este espacio semiagrícola, cuya población se había ido asentando y distribuyendo en forma aleatoria e irregular hacia el oriente del camino que iba a Valparaíso. Callejuelas y ranchos lindaban con chacras, viñas, molinos y quintas de producción frutal. Allí vivía una buena parte de los artesanos y de la población de servicio de la ciudad ${ }^{23}$.

19 Carta del obispo Diego de Medellín al rey (Santiago, 15 de abril de 1580), Lizana, 1919-1921, vol. I: 12-13. Sobre la emergencia del quechua colonial como «lengua general», Durston, 2007.

20 «Chimpa: La otra parte o vanda del rio o quebrada acequia, o cosa larga atravesada»: González Holguín, 1989 [1608]: 109-110. En la propia capital virreinal existía también una «chimba» el barrio de San Lázaro, en la otra orilla del río Rímac, reconocido también como el barrio indígena por excelencia de Lima, al menos hasta el traslado de esos grupos al nuevo espacio del Cercado, en 1590: Estenssoro Fuchs, 2003: 456-457.

21 Carta del obispo Diego de Medellín al rey (Santiago, 15 de abril de 1580), Lizana, 1919-1921, vol. I: 12-13.

22 Mellafe, 15 (Santiago, 1995): 45.

23 Según los datos proporcionados por Machado en 1614, el 30\% de los pobladores de la 
No era raro, por lo tanto, que allí se condensara una presencia importante de los indígenas. De hecho, como lo apunta Rolando Mellafe, desde su origen como barrio se nota esta tendencia, pues ocupó el espacio de un pueblo de indios que había sido trasplantado y diezmado por efecto de la misma fundación de la ciudad ${ }^{24}$. Ya en tiempos prehispánicos, sin ir más lejos, habría sido un espacio privilegiado para el asentamiento de poblaciones incaicas, en gran medida gracias a la calidad agrícola de sus tierras ${ }^{25}$. Por lo demás, el propio Pedro de Valdivia se adjudicó para sí una extensa merced ubicada más al norte, en las ricas tierras de Lampa y Colina, que antes habrían estado bajo control incaico ${ }^{26}$.

El «barrio» comenzaría a consolidarse a principios de la década de 1560, justamente con el asentamiento de algunos de los yanaconas que habían venido al servicio de los conquistadores. En efecto, fue por esas fechas cuando el grupo español organizado en el Cabildo procedió a recompensar la fidelidad y ayuda de estos andinos, incentivando su arraigo mediante la entrega de solares en ese sector; aunque existen referencias de que ya el mismo Valdivia habría hecho algunas de estas mercedes en los años inmediatamente posteriores a la fundación de Santiago. Francisco, por ejemplo, fue uno de los agraciados por el Cabildo en 1561, a través de un documento que dejaba muy en claro los elementos que hemos estado exponiendo:

[...] por que vos françisco yndio natural del peru benystes a esta tierra con los primeros conquistadores que a ella binyeron con el governador don pedro de valdiuia y en la conquista e pasificaçion de los naturales desta tierra y en la poblaçion e svstentaçion desta ziudad aveys trabaxado y seruido a su magestad muy bien y lealmente acatando lo qual y que esperamos hareys otros muchos mas seruyçios a su magestad de cada vn dia por tanto en su rreal nombre y en remuneraçion de vuestros servyçios y trabaxos vos hazemos merçed de vn solar de la ottra parte del rrio desta zibdad ${ }^{27}$.

Una veintena de andinos fueron entonces favorecidos con los terrenos, a los que se fueron agregando otros, en las décadas siguientes, a través de la compra, herencia o donación de terceros ${ }^{28}$. Así lo manifestaba Isabel, asentada

Chimba serían artesanos y ejercerían allí su trabajo: Vázquez de Espinosa, 1969 [ca. 1629]: 45.

Ruiz Rodríguez, 1986.

24 Mellafe, 15 (Santiago, 1995): 37-48.

25 Stehberg, 23 (Santiago, 1976): 3-37.

26 Cf. Stehberg y Sotomayor, manuscrito inédito.

27 Concesión del Cabildo de Santiago, 9 de mayo de 1561, Archivo Nacional Histórico, Cabildo de Santiago (ANH.CS), vol. 1 [anexo al libro Becerro], fj. 17.

28 Thayer Ojeda, 1905: 102-104. Jara y Mellafe, 1996, vol. I: 134, vol. II: 605-607. Concesiones de solares en la Chimba por parte del Cabildo de Santiago, 15 de mayo y 13 de junio de $1561 ; 10$ de abril, 24 de abril, 15 de mayo, 22 de mayo, 26 de junio y 12 de noviembre de 
en 1600 con el padre Juan Pinto, y que declaraba ser «yndia biuda muger que ffue de juan chanbo yndio del piru e hija de xripstobal yndios del cusco de aquellos que se poblaron en la chinba ${ }^{29}$.

De hecho, la mayoría de los matrimonios de indios registrados en las últimas décadas del siglo XVI y que declararon habitar en dicho espacio fueron, justamente, de personas originarias de regiones andinas y que, en su mayor parte, ejercían allí algún oficio artesanal. Barrio que ya tendría una cierta jerarquía administrativa, al contar con un alguacil mayor; cargo que, por esos años, lo ejercía Antón, natural de... $\mathrm{Cuzco}^{30}$.

Este proceso queda más claro al revisar la circulación de la propiedad de solares y los testamentos dictados por los propios indígenas. Así fue el caso, por ejemplo, del sastre Pedro Horro, «yndio del cuzco», que en 1590 vendía a Juan Cayo, otro "yndio de el cuzco», un solar que poseía en la Chimba y que había pertenecido anteriormente a Andrés, «yanacona y criado que fue de pedro de billagra $\rangle^{31}$. Diez años después, ya moribundo, Cayo nombraba a Horro como albacea de su testamento y le pedía vender ese y otro solar, vecino al anterior, con el fin de costear una serie de misas por su alma y dejar el resto del dinero a su viuda Mayora ${ }^{32}$. Esta última, por su parte, testaba dos años después, dejando en claro su origen cuzco y agregando que también lo era su padre Hernando, artesano sillero - yanacona de Hernando Escudero- a quien dejaba como herencia las dos propiedades, que al parecer aún no se habían vendido ${ }^{33}$. Algunos meses más tarde, Hernando decidía finalmente enajenar los solares, que se hallaban plantados «de viñas y arboleda», obteniendo por ellos alrededor de 300 ovejas $^{34}$.

1562, ANH.CS, vol. 1 [anexo al libro Becerro], fjs. 13-13v, 15-15v, 17v, 19, 21, 24-27v. Actas del Cabildo de Santiago, 31 de diciembre de 1566, 1. ${ }^{\circ}$ de julio de 1575 y $1 .^{\circ}$ de junio de 1576 , Colección de historiadores de Chile y de documentos relativos a la historia nacional (CHCh), Primera serie, vol. XVII: 401-402 y 445. Carta de venta de un solar en la Chimba de Diego, indio, natural del Pirú, al padre Alonso de Toledo, Santiago, 22 de octubre de 1599, ANH.ES, vol. 26, fj. 99v. Carta de venta de tres partes de dos solares en la Chimba de Francisco Moreno a Hernando, indio del Perú, Santiago, 27 de octubre de 1599, ANH.ES, vol. 26, fj. 100v. Carta de donación de un solar de Gonzalo, indio del Cuzco, a Francisco del Hoyo, su entenado, Santiago, 26 de agosto de 1602, ANH.ES, vol. 17, fjs. 210v-211.

29 Asiento de trabajo de Isabel, india, Santiago, 14 de octubre de 1600, ANH.ES, vol. 27, fjs. $202 \mathrm{v}-203$.

30 De Ramón, 4 (Santiago, 1965b): 232.

31 Carta de venta de un solar, Santiago, 27 de enero de 1590, ANH.ES, vol. 5, fjs. 99-100.

32 Testamento de Juan Cayo, Santiago, 17 de junio de 1600, Retamal Ávila, 2000: 117-118.

33 Testamento de Mayora, Santiago, 5 de febrero de 1602, Retamal Ávila, 2000: 121.

34 Carta de venta de dos solares de propiedad de Hernando, indio sillero, Santiago, 24 de octubre de 1602, ANH.ES, vol. 17, fjs. 254-255. 
También encontramos a Antón Guamantaguisa, natural de Cochabamba, que en su testamento de 1594 mencionaba estar a cargo del solar de la peruana Petrona Palla, como su albacea testamentario. El mismo era propietario de otro solar, también en la Chimba, plantado de viñas y árboles, que sería comprado, a su muerte, por su albacea, el cuzco Pedro Poma ${ }^{35}$. Por su parte, Isabel, que también se presentaba como india palla del Perú —es decir, utilizando el apelativo que en el Tawantinsuyu servía para designar a las mujeres nobles, especialmente a aquellas vinculadas con la familia del inca- compraba en 1597 un trozo de tierra «de la otra parte del Rio desta zibdad» ${ }^{36}$. Ese mismo año, el clérigo Álvaro Gómez, propietario de varios terrenos en ese sector extraurbano, ratificaba la venta que de medio solar había hecho Cecilia Gómez, «palla», a Pedro Oygua «ynga» ${ }^{37}$. En 1599 otro clérigo, Alonso de Toledo, compraba a Diego, «indio natural de el Reino de el piru», un solar que éste había heredado en la Chimba de sus padres, también inmigrantes andinos ${ }^{38}$.

Interesa subrayar el uso que hemos visto de los vocablos palla e inga, toda vez que no estamos, obviamente, ante miembros de la nobleza cuzqueña. Creemos, más bien, que su uso se debe insertar dentro del análisis que propusimos más atrás sobre el gentilicio cuzco, en el sentido de que se trataría de estrategias de gestión de identidades donde los sujetos se apropiarían de referentes sociales - cuya carga de prestigio era reconocible en el espacio andinopara hacer valer un cierto posicionamiento social entre sus pares inmigrantes o en el seno del mundo indígena local, en un contexto sui géneris de configuración de redes sociales y espaciales.

En la Chimba residía también el albañil Gaspar Guanca, originario de Jauja - que dicta testamentos y codicilios en numerosas ocasiones $(1597,1607$, 1612 y 1616) - y que hace su declaración «en la lengua del inga». Esto último revela, una vez más, la eventual permanencia — o renovación étnica - que hemos mencionado anteriormente en relación con las prácticas lingüísticas andinas observadas entre los inmigrantes del periodo. En todo caso, se descarta la hipótesis de que su ignorancia del castellano pudiera explicarse en una inmigración reciente, toda vez que la casa y huerta originales las había obtenido

35 Testamento y codicilo de Antón Guamantaguisa, Santiago, 13 y 16 de julio de 1594, Retamal Ávila, 2000: 94-95 y 114.

36 Carta de venta de un solar en la Chimba, de Martín de Fuentes a Isabel, india palla del Perú, Santiago, 25 de febrero de 1597, ANH.ES, vol. 22, fj. 248v.

37 Ratificación de Álvaro Gómez, de la venta de medio solar en la Chimba, Santiago, 8 de julio de 1597, ANH.ES, vol. 22, fjs. 341v-342.

38 Carta de venta de un solar en la Chimba, Santiago, 22 de octubre de 1599, ANH.ES, vol. 26 , fjs. $99 \mathrm{v}-100 \mathrm{v}$. 
como donación del propio Pedro de Valdivia ${ }^{39}$. Una serie de interrogantes se abren entonces sobre este sujeto: ¿Verdaderamente ignoró el castellano, por completo, hasta su muerte? Esta hipótesis es factible si consideramos que la Chimba era un espacio quechuaparlante y que en una sociedad multicultural como la santiaguina podría ser factible una cotidianeidad plurilingüe. Pero todo hace pensar que, dada su larga presencia en Chile y los lazos que tejió con la sociedad y la economía colonial, Guanca pudo poseer rudimentos de la lengua europea, si bien quizás no los consideraba suficientes como para estipular con claridad sus disposiciones testamentarias.

Leonor Titima, «yndia del cuzco», tenía dos solares en la Chimba, uno de los cuales - donde se encontraba su casa y que estaba «cercado y plantado»lindaba con el de otra $c u z c a$, Isabel, quizás la misma palla vista más arriba. En el testamento que dicta en 1601 Leonor dividía su propiedad, dejando la mitad como dote para María, hija de «ffrancisco quzco», a quien había criado desde pequeña. La otra mitad la dejaba a la familia de «pedro cuzco», «a quien tengo en lugar de hijo y esta en mi cassa». Al igual que Juan Cayo, Leonor nombraba como albaceas, además del mencionado Pedro Cuzco, al ya citado sastre andino, Pedro Horro ${ }^{40}$.

Inmigrantes más recientes, que no tuvieron acceso a las «mercedes» originales de la conquista, también tuvieron en esa zona extraurbana un espacio de llegada y de acogida, y buscaron arraigarse allí a través de la compra o el alquiler de sitios, como sucedió con el maestro sastre Juan de Luna, «yndio del cuzco», que en 1615 lo vemos arrendando un solar en la Chimba ${ }^{41}$. Vale la pena mencionar que Luna llegaría a ser elegido varias veces como «mayordomo de naturales» de la cofradía de la Candelaria, establecida hacia 1600 en el convento de San Agustín, cargo que compartió en numerosas ocasiones con otro andino, el sedero y sombrerero de Huánuco Andrés Bañado ${ }^{42}$.

Es necesaria una breve digresión para destacar aquí, en relación con las hipótesis que guían este trabajo, el carácter multicultural de dicha cofradía, tanto más relevante cuanto que en su origen había sido fundada por $-\mathrm{y}$ concebida para - negros libres, aunque rápidamente adquirió un contenido plural al incorporar al mundo indígena de la ciudad. Así aparece indicado desde 1610 en

39 Testamentos de Gaspar Guanca, Santiago, 21 de julio de 1597 y 2 de junio de 1612, Retamal Ávila, 2000: 104-106 y 137-138.

40 Testamento de Leonor Titima, Santiago, 20 de enero de 1601, Retamal Ávila, 2000: 118-120.

41 Arriendo de un solar en la Chimba, de Juanes de Herrera a Juan de Luna, Santiago, 9 julio 1613, ANH.ES, vol. 46, fj. 56.

42 Valenzuela Márquez, 43 (Santiago, 2010a). 
sus constituciones, donde se la definía como una entidad integrada por «mulatos orros» y por «naturales oficiales», dando cuenta, con esto último, de la preeminencia otorgada al ingreso de indígenas que ejercieran como artesa$\operatorname{nos}^{43}$. La misma pluralidad podemos observarla en otra de las cofradías preferida por los inmigrantes estudiados, la de Nuestra Señora de Copacabana que, si bien había sido definida como «cofradía de los indios naturales de esta ciudad», en ella también sociabilizaban su catolicismo, indígenas provenientes del valle central (Rapel), de la Araucanía (Villarrica) e, incluso, de la lejana isla de Chiloé, además de los aún más lejanos inmigrantes andinos. Sin ir más lejos, la primera información que encontramos de esta corporación aparece en el testamento de un indio originario del Tucumán en 160844; mientras que, medio siglo más tarde, su mayordomo era el zapatero quiteño Andrés Machado ${ }^{45}$.

Volviendo a nuestro análisis sobre la Chimba como espacio de inserción de inmigrantes andinos más tardíos, vemos que esta misma tendencia se puede observar entre sus descendientes, como Catalina «yndia del cuzco naçida en esta tierra, hija de juan y de ynes yndios de el cuzco», que en 1591 testaba un solar en la Chimba ${ }^{46}$. Isabel de Gálvez, por su parte, hija mestiza de una india originaria de la región de Quito, se casó en 1587 con el sastre mestizo - y probablemente nieto de india cuzqueña- Juan Chico de Peñalosa, aportando una dote que se concretó en 450 pesos y una chacra en la Chimba, herencia de su padre español. El mismo Chico vivía en ese barrio, junto al cascajal del río, y llevó a vivir con ellos a la madre quiteña de Isabe ${ }^{47}$.

Por último, también vemos a un escribano desplazándose en 1619 hasta la Chimba para registrar el testamento del moribundo Lorenzo Ramírez Yáñez, ladino nacido en Santiago, pero cuya madre había sido «yndia cuzca» y con un solar que lindaba «calle en medio» con los de otros indígenas ${ }^{48}$. Otra habitante de ese arrabal hacia mediados del siglo XVII era la india Luisa de Araya, cuyo origen se desconoce pero que era casada con el cuzco Francisco de Chaves ${ }^{49}$.

43 Constituciones de la cofradía, transcritas en Falch, 13 (Santiago, 1995): 26.

44 Testamento de Alonso Rodríguez, La Chimba, 26 de agosto de 1608, ANH.ES, vol. 45, fjs. 494-494v.

45 Profundizamos este tema en Valenzuela Márquez, 43 (Santiago, 2010a).

46 Testamento de Catalina, Santiago, 1..$^{\circ}$ de agosto de 1591, ANH.ES, vol. 6, fjs. 251$251 \mathrm{v}$.

47 Testamento de Isabel de Gálvez, Santiago, 24 de agosto de 1589, ANH.ES, vol. 6, fjs. 9-10v. De Ramón, 2004a: 96-100.

48 Testamento de Lorenzo Ramírez Yáñez, Santiago, 24 de mayo de 1619, Retamal Ávila, 2000: 160-161.

49 Testamento de Luisa de Araya, Santiago, 11 de diciembre de 1645, Retamal Ávila, 2000: 183-185. 


\section{INSERCIÓN ECONÓMICA, VINCULACIÓN CULTURAL Y MOVILIDAD SOCIAL}

Lo visto en el punto anterior ya nos anuncia una clara y sostenida vinculación, al menos de los inmigrantes que testaron en Santiago, con el sistema económico y con la estructura social locales, y a partir de un posicionamiento socioétnico «privilegiado» dentro de los grupos «subalternos» de la ciudad.

Por cierto, estamos ante una aproximación empírica fragmentaria y con un grado de representatividad relativa, considerando que son menos de treinta los testamentos de actores andinos con los que contamos, además de otros indicios documentales que los complementan. Se trata, no obstante, de individuos que han logrado cierta autonomía material e inserción social, pese a su condición de indígena y de forastero - o descendiente de ellos-. En este sentido, como apunta Pablo Rodríguez, los indígenas que testan son los más integrados en la sociedad colonial y en sus prácticas administrativas, hasta tal punto que recurren a este mecanismo jurídico occidental para dejar una declaración escrita de sus deseos y herencias, materiales e inmateriales ${ }^{50}$. Este carácter «elitista» también quedaría confirmado por la doble dirección que asume la relación entre el testamento y el oficio: por un lado, la mayoría de los artesanos indígenas que testan son inmigrantes andinos o provenientes de regiones ligadas al espacio peruano-quiteño; en sentido inverso, la mayoría de los andinos que aparecen en esos testamentos son artesanos, predominando los oficios dedicados a la confección de vestuario.

Así, entre los artesanos inmigrantes que testan encontramos a Gaspar Guanca, de Jauja (albañil); Pedro Poma, de Guayaquil (sastre); Agustín Collaguaco, quiteño (sedero y sombrerero); Juan Babicicayo, de Huamanga (sastre); Alonso, de Puerto Viejo (carpintero); Pedro Lima, natural de la capital virreinal (oficial de sastre); Andrés Bañado Pongo, de Huánuco (sedero y sombrerero); Bernabé Félix, originario de la región de Pisco (oficial de sastre); Andrés Machado, quiteño (maestro zapatero); Antonio de la Vega Pomayere, originario de Jauja (sombrerero, tintorero y comerciante).

Por su parte, los tres cuzcos que recoge Juan Guillermo Muñoz en su repertorio de pobladores de Chile entre 1565 y 1580 aparecen con un cierto nivel de integración en la sociedad y en la economía que se estaba delineando. Antón Chile Viracocha, por ejemplo, no sólo ejercía como sastre sino que en 1576 se le ve incluso participando en el avío de la soldadesca que partía con el gobernador Rodrigo de Quiroga a combatir a los insumisos mapuches del sur. Al pa-

50 Rodríguez Jiménez, 2002: 17. 
recer, su participación fue más allá de la confección de los escaupiles ${ }^{51}$ requeridos puesto que, además de su paga, se le premiaría con una pieza de ropa. Su hijo Lucas incluso llegaría a participar en la campaña militar del año siguiente, entre los indios auxiliares que acompañaron a la tropa hispana en un nuevo intento por controlar la Araucanía ${ }^{52}$.

A todos ellos habría que agregar a los cuzcos Hernando y Diego de Castro, hermanos y sastres. El primero de ellos sabía firmar con su nombre y poseía una pequeña tienda en la ciudad. Diego, por su parte, si bien aparece en su testamento como «criollo de esta tierra», declaraba ser hijo de «indios del Cuzco»; y en el asiento que había concertado años antes con su hermano para ser su aprendiz se había presentado abiertamente como «yndio del cuzco» ${ }^{53}$.

A ellos agregamos también, para efectos de nuestro análisis, a los descendientes de segunda generación o a quienes manifestaron estrechas relaciones familiares o identitarias con el espacio andino, como el ya citado Diego de Castro, el albañil Rodrigo — que, si bien nació en Coquimbo, declaraba ser «natural» de Quispicanchis, en la región de Cuzco-, el herrero Diego Mejía —originario de Quito - o el sastre Lorenzo Ramírez Yáñez — hijo mestizo de cuzca que, como muchos de los ejemplos que estamos analizando, combinaba su actividad artesanal con el cultivo de viñas y arboledas que tenía plantadas en su solar de la Chimba ${ }^{54}$ - Si bien estas personas deberían entrar en un registro diferente, pues generalmente se trata de mestizos biológicos o «españolizados», lo cierto es que no deja de ser interesante vincularlos en una misma lógica de inserción social y de construcción patrimonial.

Emma de Ramón nos muestra, así, el ejemplo del sastre limeño Sebastián de Iturrieta que, si bien mestizo, tenía una madre cuzqueña y el mismo declaraba abiertamente dicho origen. A lo largo de su vida conocida, desplegada desde que llegó a Santiago a comienzos de la década de 1580 y a lo largo de la primera década del siglo siguiente, mostró una constante relación con indígenas provenientes de los Andes, a quienes asentaba como aprendices o contrataba como oficiales en caso de necesitar artesanos de calidad que apoyaran su prominente carrera. Esta última lo llevó no sólo a convertir su taller en uno de

51 Especies de corazas o armaduras, acolchadas de algodón, que se ponían los habitantes prehispánicos de México para protejerse de las flechas.

52 Muñoz, 1989: 85 y 149.

53 Asiento de Trabajo como aprendiz de sastre de Diego de Castro, Santiago, 15 de febrero de 1591, ANH.ES, vol. 7, fjs. 305v-306. De Ramón, 2 (Santiago, 2004b): 42-47. Testamento de Diego, Santiago, 6 de mayo de 1613), Retamal Ávila, 2000: 142-144.

54 Testamento de Rodrigo, Santiago, 5 febrero 1612, Retamal Ávila, 2000: 136. Testamento de Diego Mejía, Santiago, febrero de 1619, ANH.ES, vol. 59, fjs. 95-95v. Testamento de Lorenzo Ramírez Yáñez, Santiago, 24 de mayo de 1619, Retamal Ávila, 2000: 161. 
los más cotizados de la capital sino también a explorar otros negocios, vendiendo bastimentos y carretas de los indios del partido de Santiago. También compró a los indígenas de Aconcagua - a través del Protector de Naturalesalgunos «pedasos de tierra» en la serranía superior de ese valle —al norte de Santiago-, los cuales dio en dote a una hija — aunque luego los vendería a un tercero- ${ }^{55}$. El sastre Iturrieta demostró, así, una contundente capacidad de utilizar sus raíces andinas y también su origen mestizo, ascendiendo en el plano económico - con un patrimonio que a su muerte ascendía a cerca de dos mil pesos - y en el de las redes sociales urbanas — uno de sus matrimonios incluso llegó a vincularlo con Alonso del Campo Lantadilla, poderoso miembro de la elite local一. Ascenso social que también incluyó «inversiones» en el plano simbólico, como la compra de una sepultura familiar en un lugar destacado de la iglesia de la Merced de Santiago, que además sirvió para posicionar a su «linaje» —en términos hispánicos - puesto que se trató de un espacio reservado contractualmente para servir de asiento destacado a sus descendientes que asistiesen a los oficios religiosos ${ }^{56}$.

En la misma línea retomamos el caso ya expuesto de otro sastre y mestizo, Juan Chico de Peñalosa, que había nacido en Concepción hacia 1553 y que probablemente era nieto del también sastre de origen sevillano Juan Chico, quien había llegado en la hueste de Pizarro y se había instalado con una pequeña encomienda en la región de Jauja. Cuando se fundó Lima, en 1535, se trasladó a vivir a esta ciudad junto con su concubina indígena que había traído del Cuzco y con la cual tuvo tres hijas mestizas, falleciendo al año siguiente. Es posible que alguna de ellas haya emigrado a Chile y procreado, de Antón de Nápoles, al nieto homónimo que hacia fines de siglo vemos ejerciendo, con el mismo oficio que su abuelo, en la capital chilena ${ }^{57}$. Pese a ser de tercera generación —en términos de su herencia biológica andina - llama la atención su intensa vinculación cultural con el mundo de los inmigrantes directos. De hecho, como vimos, estuvo casado con otra mestiza hija de india quiteña. Además, conocía perfectamente la lengua quechua; tanto así que fue él quien actuó como traductor en el ya citado testamento del albañil Gaspar Guanca, originario de Jauja — la misma región donde el posible abuelo de Chico había tenido

55 Carta de venta de Sebastián de Iturrieta y Juan de Castro, de dos terrenos en el valle del Aconcagua a Manuel González, Santiago, 28 marzo 1615, ANH.ES, vol. 83, fjs. 33-35.

56 De Ramón, 2004a: 100-102. Valenzuela Márquez, 43 (Santiago, 2010a).

57 Lockhart, 1987: 173-174. Thayer Ojeda, 1939, vol. I: 277. De Ramón, 2004a: 96-97. Ver el pleito que se ventiló en España, entre 1544 y 1548, sobre los bienes dejados a su muerte por el sastre sevillano, entre su sobrina, Estebanía Chica, vecina de Sevilla, y una de sus hijas mestizas, Inés Chica: AGI, Justicia, vol. 746, leg. 5. 
su encomienda- Guanca era su vecino en la Chimba y, como ya dijimos, había declarado que no hablaba castellano. Por cierto, el otro testigo del testamento de este andino fue un hijo natural de Chico, Francisco Tamayo, que también entendía el quechua ${ }^{58}$.

Otra asociación que podemos hacer entre Chico y Guanca, además de su proximidad geográfica (la Chimba) y cultural (los Andes) es en torno a la evolución de su patrimonio. En efecto, vemos que la propiedad suburbana que aportó la mestiza Isabel de Gálvez como dote al matrimonio con Chico siguió prosperando más allá de la muerte, a los pocos años, de su dueña, a tal punto que más tarde serviría como herencia para el ya citado hijo del sastre, Francisco Tamayo. Consistente en una cuadra de tierra - es decir, el equivalente a cuatro solares - con viña, lagar, bodega, casa y frutales, la parcela fue destinada a sustentar una capellanía fundada en favor de las almas de Juan e Isabel, a cuyo cargo quedaría el propio Tamayo cuando más tarde profesara como sacerdote ${ }^{59}$.

En el caso de Guanca, por su parte, llama la atención de que, pese a declarar que sólo hablaba quechua - quizás, como hemos dicho, porque consideraba su eventual conocimiento del castellano a un nivel demasiado básico como para establecer con claridad sus deseos testamentarios- logró hacer fructificar el solar que se le había donado en los años de la conquista y, ya al final de sus días, declaraba que «por la yndustria y travaxo de ambos [ - con su esposa, india jurí del Tucumán-] adquirieron bienes muebles y raysses». Una integración económica y social que lo llevó a construir una pequeña fortuna personal que incluía «tres solares y cassas» en la Chimba, —una de ellas de tejaplantados con viñas y olivos ${ }^{60}$. Ya en su primer testamento de 1597 además de estas propiedades, arboledas, viñas, tinajas con vino y herramientas de uso agrícola, dejaba en herencia cincuenta pesos «de buen oro» ${ }^{61}$. Su nivel de acumulación lo llevó incluso, en 1608, a instituir una capellanía de misas —ins-

58 Testamento de Gaspar, La Chimba, 23 de noviembre de 1616, ANH.ES, vol. 80, fjs. 190-191v. Juan Chico también había participado como testigo en el testamento que Gaspar dictó tres años antes: Testamento de Gaspar, «indio natural de Jauja», La Chimba, 3 de septiembre de 1613, ANH.ES, vol. 81, fjs. 309v-310v.

59 Testamento de Isabel de Gálvez, Santiago, 24 de agosto de 1589, ANH.ES, vol. 6, fjs. 9-10v. Carta de donación de Juan Chico y Beatriz Tamayo, de su casa en la Chimba a su hijo Francisco Tamayo, Santiago, 15 de abril de 1615, ANH.ES, vol. 53, fjs. 220-221. De Ramón, 2004a: 96-100.

60 Testamentos de Gaspar Guanca, Santiago, 21 de julio de 1597 y 2 de junio de 1612 , Retamal Ávila, 2000: 104-106 y 137-138.

61 Testamento de Gaspar Guanca, Santiago, 21 de julio de 1597, Retamal Ávila, 2000: 105. 
tancia normalmente asociada a las élites-, apareciendo bajo el nombre de Gaspar Atucaupa, «yndio natural del balle de Jauja». Para financiarla dejó los réditos producidos por «una cassa viña e guerta quen tengo en la chimba» y estipuló como capellanes a los hijos del rico mercader Diego Sánchez Mirabal ${ }^{62}$. Cuatro años más tarde decidía cambiar el destino espacial de la capellanía - en principio vinculada al convento de Santo Domingo - designando ahora al convento de San Agustín. La decisión estuvo influida, sin duda, por la relación afectiva que Guanca habría tejido con el mercader citado - «diffunto a quien tube grande amor»- quien estaba enterrado con su familia, justamente, en la iglesia agustina. La importancia que Gaspar asignaba a esta decisión se vió reflejada al incorporar otro de sus solares de la Chimba para sustentar el servicio de la capellanía, que ahora ascendía a 400 pesos $^{63}$. Vemos entonces que el indio Guanca, yanacona inmigrante que quizás no aprendió la lengua castellana o lo hizo débilmente, no sólo logró insertarse materialmente en el mundo colonial que se estaba consolidando en la urbe chilena, sino también construir cierta red - al parecer afectivo-paternalista - con un miembro poderoso de la sociedad española.

Otro indígena de Jauja, Antonio de la Vega Pomayere, alcanzó a ser un próspero sombrerero y tintorero con tienda arrendada en la ciudad a Gaspar de Ahumada, al mismo tiempo que realizaba inversiones en actividades comerciales. Entre éstas, declaraba que el jesuita Francisco Ferreira le debía la cuantiosa suma de 1.400 pesos «que le di para que me los llebase a emplear a la ciudad de los Reyes en tiempo que hizo viaje a dicha ciudad» y que el general Pedro Prado le debía más de 200 pesos «que le di para que me comprare sevo», entre otros deudores que menciona. En su testamento, dictado en 1668, se registran numerosos bienes, entre los cuales destacaba una casa en la traza de la ciudad con un valor de más de 500 pesos, 300 de los cuales los había pagado al contado ${ }^{64}$.

El sastre Pedro Poma, que era guayaquileño por nacimiento — pero cuzco por identificación andina- había estado al servicio del obispo Diego de Medellín llegando a desempeñarse como sacristán en la catedral ${ }^{65}$ y residía en la

62 Carta de institución de capellanía por Gaspar Atucaupa, Santiago, 18 de junio de 1608, ANH.ES, vol. 38, fjs. 199-199v. En otros lugares del continente, en todo caso, la instauración de capellanías y obras pías no era infrecuente entre artesanos y cofrades de grupos sociales y étnicos diferentes a los hispanocriollos acomodados: Celestino y Meyers, 1981: 123.

63 Carta de institución [-traslado-] de capellanía de Gaspar Guanca, La Chimba, 2 de junio de 1612, ANH.ES, vol. 49, fjs. 257-258.

64 Testamento de Antonio Felipe de la Vega Pomayere Coraca, Santiago, 20 de mayo de 1668, Retamal Ávila, 2000: 208-211.

65 Archivo del Arzobispado de Santiago (AAS), Parroquial, Parroquia del Sagrario, vol. 1, libro 1 , fjs. 216v, 261v y $265 \mathrm{v}$. 
Chimba cuando testó en 1598. Entre sus bienes estaba el solar plantado con viñas y arboleda que vimos había adquirido a la muerte del cochabambino Antón Guamantaguisa, algunos años antes, el que dejó como herencia al convento de San Agustín. Pero, además, su extenso testamento detalla numerosas piezas de vestir - algunas de ellas de origen andino - e incluso un par de pinturas religiosas —una de ellas traída de México—66.

Por otro lado, la construcción de redes sociales y laborales entre andinos inmigrantes o entre los descendientes mestizos que poblaban el universo pluriétnico y multicultural de la capital chilena y sus arrabales no sólo se daba en el contexto laboral —oficios artesanales - o espacial — la Chimba-, sino también en el plano de las prácticas culturales y religiosas, como hemos estudiado en otro lugar ${ }^{67}$. Así, por ejemplo, podemos identificar a personas donde confluyen su lugar de residencia y una cofradía en común - la Candelaria de San Agustín - en el trío formado por el hijo de cuzca Lorenzo Ramírez Yañez y los andinos Pedro Lima y Andrés Bañado Pongo. Sus oficios, por cierto, eran vinculantes, en la medida en que los dos primeros ejercían como sastres y Bañado era sedero y sombrerero. Por lo demás, este último será uno de los albaceas del testamento de Lima, quien lo denomina como «my compadre» ${ }^{68}$. Sobre Bañado, quien llegó a Chile hacia 1600, es interesante constatar que al momento de testar en 1624 declaraba estar casado con una india llamada Inés y que «cuando nos casamos no teníamos nada». Sin embargo, a la fecha había logrado acumular no sólo cierto patrimonio material equivalente al de un artesano urbano medianamente acomodado — que incluía un esclavo negro por el que pagó cien patacones - sino también una red de clientes y de vinculaciones con otros artesanos que sin duda avalaban el posicionamiento que hemos visto a nivel de la cofradía agustina ${ }^{69}$.

Observando estas experiencias, habría que relativizar lo planteado por Ramón Gutiérrez para el mundo de los artesanos coloniales americanos. Según este autor, el origen modesto de los artesanos - en términos materiales y «raciales» - pero sobre todo el hecho de formar parte de una actividad que la sociedad veía con un carácter funcional -incluso en áreas mejor consideradas, como la sastrería y la platería - implicaría un «lastre» social que les habría

66 Testamento de Pedro Poma, Santiago, 17 de agosto de 1598, Retamal Ávila, 2000: 113-116. Thayer Ojeda, 1905: 105.

67 Valenzuela Márquez, 43 (Santiago, 2010a).

68 Testamento de Pedro Lima, Santiago, 22 de octubre de 1621, Retamal Ávila, 2000: 166-167.

69 Testamento de Andrés Bañado Pongo, Santiago, 16 de marzo de 1624, ANH.ES, vol. 87 , fjs. 132-133v. 
impedido la movilidad social, aun cuando adquiriesen cierto éxito económico $^{70}$.

Por cierto, no pretendemos generalizar las experiencias de integración y movilidad socioeconómica que hemos visto en los párrafos precedentes, pero sí dar cuenta de que, al menos en esa porción de sujetos — de los cuales poseemos documentación específica - su condición de indígena, de forastero y de artesano constituyeron elementos que más bien colaboraron en su proceso de inserción postmigratoria.

Incluso se han mencionado casos de mujeres, que no figuraban en categorías artesanales, que lograron posicionarse material y socialmente, a veces aprovechando los espacios que ofrecían el concubinato o el servicio personal para algún amo español del cual pudieron recibir legados testamentarios que procuraron bienestar económico y una posición relativamente destacada en la sociedad. Ese fue el caso, por ejemplo, de Inés González, «india natural de las provincias del Pirú», que había sido sirviente del primer obispo de Santiago y del cual recibió una importante chacra en la zona de Conchalí —en las afueras de la capital - donde al momento de testar (1564) se encontraban trabajando quince yanaconas, entre hombres y mujeres, además de diez indígenas provenientes de otra encomienda ${ }^{71}$. Otras, como la hija de india quiteña Isabel de Gálvez, recibieron su propiedad como herencia de su padre español, mientras que la mayoría de las que se mencionaron a lo largo del artículo, al parecer, las obtuvieron como herencia de sus maridos, aquellos yanaconas andinos que fueron agraciados con las mercedes originarias del Cabildo santiaguino. Destacan algunas, como la ya mencionada Leonor Titima, que además de sus dos solares en la Chimba declaraba entre sus bienes «cien pessos en oro que tengo en mi caxa» ${ }^{72}$.

Para finalizar, queremos destacar el hecho de que, junto con la actividad artesanal y el acceso a bienes raíces, los andinos y sus descendientes directos utilizaron estas propiedades para llevar a cabo actividades agrícolas ligadas a las viñas y los olivares, que continuamente aparecen en los registros notariales como parte de la existencia productiva de los solares que se traspasaban por venta o herencia ${ }^{73}$. En efecto, tanto Antón Guamantaguisa como Juan Cayo y

70 Ramón Gutiérrez, «Los circuitos de la obra de arte, artistas, mecenas, comitentes, usuarios y comerciantes», cit. en De Ramón, 2004a: 95.

71 Testamento y codicilios de Inés González, Santiago, 21 de noviembre, 5 de diciembre y 13 de diciembre de 1564, Jara y Mellafe, 1996, vol. I: 202-207, 210-212 y 217. Retamal Ávila, 12 (Santiago, 1996): 49-76. Ruiz Rodríguez, X/1 (Santiago, 2006): 81.

72 Testamento de Leonor Titima, Santiago, 20 de enero de 1601, Retamal Ávila, 2000: 119.

73 Madariaga Varela, 6 (Santiago, diciembre de 2006). 
su familia, Pedro Poma, Leonor Titima o los mestizos Lorenzo Ramírez y Juan Chico - junto a su familia quiteña-, declararon este tipo de plantaciones así como tinajas e implementos necesarios para producir y almacenar el vino. El sastre Chico también aparece como testigo en la escritura de donación de un solar que Gonzalo, «yndio ladino de el cusco», tenía «en la otra parte de el rrio», el cual se hallaba «plantado de viña y otras cossas de arboleda» ${ }^{74}$. Con respecto a Cayo, por ejemplo, el inventario de los bienes que dejó a su muerte, si bien revelaba una existencia modesta, contemplaba, además de los dos solares «plantados de biña y arboleda», «un lagarsillo a manera de caja biejo», «dos tinajas grandes llenas de bino atapadas», «otra tinaja baçia» y «tres tinajillas chiquillas vaçias» ${ }^{75}$. Sin ir más lejos, vimos que el próspero Gaspar Guanca poseía tres solares donde campeaban las viñas y olivos, parte de cuyo patrimonio pasó a su hija Ana como dote matrimonial. Así, en 1639, esta última declaraba poseer aún dos de estos solares heredados en la Chimba, en los cuales se encontraba «una biñita y cassa de texa, y un lagar de madera breado y dos tinaxas. La una de veinte arrobas y la otra de diez e nueve» ${ }^{76}$.

De esta manera, parras, olivos y frutales formaron parte de la trilogía mediterránea importada por los hispanos que fue rápidamente incorporada y generalizada entre las economías familiares y en el habitat cotidiano de los habitantes de la Chimba, inmigrantes indígenas incluidos. De hecho, toda la zona norte de Santiago se caracterizaba por producir abundante mosto, en una actividad que comenzó ya desde muy temprano en la conquista y para la cual, además, se requería poco riego y no se necesitaban grandes extensiones de tierra, ya que bastaba apenas una cuadra para plantar algunas parras y procurar al menos para el autoconsumo. Armando de Ramón llega a decir que en aquellos sectores suburbanos de la Chimba y Renca el cultivo agrícola casi no tenía otro objetivo que la producción de vino y aguardiente ${ }^{77}$.

74 Carta de donación de un solar de Gonzalo, indio del Cuzco, a Francisco del Hoyo, su entenado, Santiago, 26 de agosto de 1602, ANH.ES, vol. 17, fjs. 210v-211.

75 Inventario de bienes de Juan Cayo, indio del Cuzco, La Chimba, 6 de julio de 1600, ANH.ES, vol. 16, fjs. 195-195v.

76 Testamento de Ana Jauja, Santiago, 2 de febrero de 1639, Retamal Ávila, 2000: 179-181.

77 De Ramón, 1978: 144. Ruiz Rodríguez, X/1 (Santiago, 2006): 55-92. 


\section{RECAPITULANDO}

A guisa de conclusiones quisiéramos destacar algunos puntos que hemos desplegado a lo largo del texto. En primer lugar, la complejidad cronológica de la inmigración andina en Chile central, configurada por grupos sucesivos que habrían comenzado por los diversos mitimaes trasladados en tiempos incas; traslados que habrían tenido una sucesión definitiva y trascendente a partir de los cientos de yanaconas que llegaron junto con la invasión de los primeros conquistadores así como grupos menores asociados a huestes de apoyo más tardías; y, por último, las inmigraciones más individuales y difíciles de detectar, asociadas a las compulsiones laborales y desintegraciones comunitarias que trastocaron el continente y motivaron desplazamientos humanos a lo largo de todo el periodo colonial.

Un segundo aspecto que se desprende de la información analizada es la diversidad regional y, por lo tanto, étnica de dichos inmigrantes; diversidad que contribuyó de manera decisiva a la conformación fundacional de la sociedad pluriétnica y multicultural que se desarrolló en la capital chilena. Queda por estudiar en profundidad, eso sí, las relaciones internas y las redes laborales, de parentesco - biológico o espiritual — y de amistad que se evidencian en la documentación revisada.

En tercer lugar y derivado de lo anterior, hemos visto la intensa y secular concentración espacial de muchos de estos inmigrantes en un barrio específico de la «otra ciudad», la no-castellana, donde la convivencia con otros grupos - otros indígenas forasteros, negros, hispanos pobres, mestizos - podría haber permitido la generación de un sector suburbano pluricultural y de cotidianos lazos interétnicos. Lazos basados, justamente, en la vecindad, el trabajo compartido - como en el caso de los artesanos - y eventuales alianzas familiares.

En el plano laboral, justamente, la documentación nos informa de un segmento importante - al menos cualitativamente hablando- que se ha integrado al sistema colonial, ejerciendo una actividad laboral calificada, construyendo un patrimonio y accediendo a testamentos y escrituras notariales para vincular sus bienes y contratar servicios de terceros.

Detectamos aún un gran vacío - y, por lo tanto, un gran desafío- en lo que respecta a las formas y contenidos culturales que practicaban dichos inmigrantes y sus descendientes pues, según hemos expuesto con alguna información fragmentaria, existían sujetos en el espacio urbano $-\mathrm{y}$ también en el mundo rural- que mantenían el uso del idioma quechua aún después de muchos años de inserción local. Nos permitimos volver a subrayar, en este plano, el caso de Gaspar Guanca, que testó en esa lengua, pese a que su historial de 
bienes y de relaciones revelaba una integración evidente e intensa con la sociedad y la economía locales. Integración que incluso lo llevó a establecer una capellanía y a vincularla afectivamente con la tumba de un poderoso mercader de la época.

Queda abierto el tema de los descendientes, de sus herencias - materiales y culturales - y de sus vinculaciones cruzadas con los ancestros inmigrantes y el mundo colonial chileno. Mundo este último que, pese a ser su espacio de origen $-\mathrm{y}$ donde, formalmente, no podrían ser catalogados como forasteros-, sigue refiriéndose a ellos bajo la categoría de cuzco.

Es a partir de esta categoría, justamente, que hemos analizado el proceso identitario que vive la mayoría de los inmigrantes estudiados - independientemente de su origen geográfico efectivo-, en lo que se refiere a la generalización del uso del concepto cuzco, que adopta una representación intermedia entre «gentilicio»y «etnónimo», y que es utilizado como referente identitario tanto por parte del sistema colonial como por ellos mismos. Una autoidentificación con implicancias sociopolíticas, en la medida en que buscaba captar y gestionar estratégicamente el concepto hispano de benemérito, asociándolo a los yanaconas que ayudaron a los conquistadores a extender la soberanía real. Esta estrategia implicaba la generación de una «memoria» que vinculara a los descendientes - reales o asociados imaginariamente por la vía de la adscripción a dicho gentilicio panandino - y que permitiría, virtualmente, generar espacios de negociación con el sistema colonial, haciendo valer una condición privilegiada y distintiva en relación con el resto de los grupos indígenas y mestizos que habitaban la ciudad.

Esta búsqueda de distinción bourdiana ${ }^{78}$, no obstante, se articulaba cómodamente en medio de un proceso de integración social, acumulación patrimonial y generación de redes individuales y corporativas que funcionaban en un registro abiertamente pluriétnico y multicultural, acorde con la diversidad que bullía en la capital chilena de esos años; urbe que se caracterizaba por presentar una sociedad abierta a recibir y a integrar a inmigrantes de distintas regiones y condiciones étnicas como parte de su conformación y funcionamiento.

\section{BIBLIOGRAFÍA}

Barros Arana, Diego, Historia general de Chile, Santiago, Editorial Universitaria/DIBAM, 1999-2005 [1884-1902], 16 vols.

78 Bourdieu, 1979. 
Borah, Woodrow y Cook, Serborne F., «The Urban Center as a Focus of Migration in the Colonial Period: New Spain», Richard P. Schaedel et al. (eds.), Urbanization in the Americas from its Beginnings to the Present, Chicago, Walter De Gruyter, 1978: 383-398.

Bourdieu, Pierre, La distinction. Critique sociale du jugement, Paris, Les Editions de Minuit, 1979.

Castro Gutiérrez, Felipe, «Migración indígena y cambio cultural en Michoacán colonial, siglos XVII y XVIII», Colonial Latin American Historical Review, VII/4 (Albuquerque, 1998): 419-440.

Charney, Paul, «Negotiating Roots: Indian Migrants in the Lima Valley during the Colonial Period», John E. Kicza (ed.), The Indian in Latin American History. Resistance, Resilience, and Acculturation, Wilmington (DE), Scholarly Resources Inc., 2000: 139-156.

Celestino, Olinda y Meyers, Albert, Las cofradias en el Perú: región central, Frankfurt, Verlag Klaus Dieter Vervuert, 1981.

Colección de historiadores de Chile y de documentos relativos a la historia nacional, primera serie (1558-1705), Santiago, Imprenta Elzeviriana, 1898-1915, 30 vols.

Cornejo, Luis, «Los Inka y sus aliados Diaguita en el extremo austral del Tawantinsuyu», Jorge Hidalgo (et al.), Tras la huella del Inka en Chile, Santiago, Museo Chileno de Arte Precolombino, 2001: 75-129.

Cook, Noble David, «Les indiens immigrés à Lima au début du XVII ${ }^{\mathrm{e}}$ siècle», Cahiers des Amériques Latines, 13-14 (Paris, 1976): 33-50.

De Ramón, Armando, «La sociedad española de Santiago de Chile entre 1581-1596 (Estudio de grupos)», Historia, 4 (Santiago, 1965a): 191-228.

De Ramón, Armando, «Bautizos de indígenas según los libros del Sagrario de Santiago correspondientes a los años 1581-1596», Historia, 4 (Santiago, 1965b): 229235 .

De Ramón, Armando, «Santiago de Chile, 1650-1700» [primera parte], Historia, 12 (Santiago, 1974-1975): 93-373.

De Ramón, Armando, «Santiago de Chile, 1650-1700» [segunda parte], Historia, 13 (Santiago, 1976): 97-270.

De Ramón, Armando, «Santiago de Chile. Industria artesanal y servicios», Armando de Ramón (comp.), Historia urbana. Una metodología aplicada, Buenos Aires, CLACSO/Siap, 1978: 135-168.

De Ramón, Armando, Santiago de Chile (1541-1991). Historia de una sociedad urbana, Madrid, MAPFRE, 1992.

De Ramón, Emma, «Juan Chico de Peñalosa, Sebastián de Iturrieta y Martín García, tres sastres en los albores de la industria santiaguina: 1560-1620», Julio Retamal 
Ávila (ed.), Estudios coloniales III, Santiago, Universidad Andrés Bello, 2004a: 95-112.

De Ramón, Emma, «La incorporación de las etnias no hispanas a la actividad industrial durante la colonia temprana», Revista Archivo Nacional, 2 (Santiago, 2004b): 42-47.

Durston, Alan, Pastoral Quechua: The History of Christian Translation in Colonial Peru, 1550-1650, Notre Dame (IN), University of Notre Dame Press, 2007.

Espinoza Soriano, Waldemar, Los incas. Economía, sociedad y estado en la era del Tahuantinsuyo, Lima, Amaru, 1997 [1987].

Estenssoro Fuchs, Juan Carlos, Del paganismo a la santidad. La incorporación de los indios del Perú al catolicismo, 1532-1750, Lima, IFEA/PUCP, Instituto RivaAgüero, 2003.

Estenssoro Fuchs, Juan Carlos, «Construyendo la memoria: la figura del inca y el reino del Perú, de la conquista a Túpac Amaru II», Thomas Cummins (et al.), Los incas, reyes del Perú, Lima, Banco de Crédito del Perú, 2005: 93-173.

Falch, Jorge, «Cofradía de Nuestra Señora de la Candelaria de los mulatos en el Convento de San Agustín de Santiago de Chile», Anuario de historia de la Iglesia en Chile, 13 (Santiago, 1995): 17-30.

González Holguín, Diego, Vocabulario de la lengua general de todo el Perú llamada lengua qquichua o del inca, Lima, Universidad Nacional Mayor de San Marcos, 1989 [1608].

Jara, Álvaro, «Los asientos de trabajo y la provisión de mano de obra para los no-encomenderos en la ciudad de Santiago, 1586-1600» [1959], Álvaro Jara (comp.), Trabajo y salario indígena. Siglo XVI, Santiago, Universitaria, 1987: 59-63.

Jara, Álvaro y Mellafe, Rolando (comp.), Protocolos de los escribanos de Santiago. Primeros fragmentos, 1559 y 1564-1566, Santiago, DIBAM, 1996, 2 vols.

Kellogg, Susan y Restall, Matthew (eds.), Dead Giveaways. Indigenous Testaments of Colonial Mesoamerica and the Andes, Salt Lake City, University of Utah Press, 1998.

León, Leonardo, «Expansión inca y resistencia indígena en Chile, 1470-1536», Chungará, 10 (Arica, 1983): 95-115.

León, Leonardo, «La guerra de los Lonkos en Chile central. 1536-1545», Chungará, 14 (Arica, 1985): 91-114.

Lizana, Elías (comp.), Colección de documentos históricos recopilados del Archivo del Arzobispado de Santiago, Santiago, Imprenta de San José, 1919-1921, 4 vols.

Lockhart, James, Los de Cajamarca. Un estudio social y biográfico de los primeros conquistadores del Perú, Lima, Milla Batres, vol. II, 1987. 
Lorandi, Ana María y Rodríguez, Lorena, «Yanas y mitimaes. Alteraciones incaicas en el mapa étnico andino», Ana María Lorandi, Carmen Salazar-Soler y Nathan Wachtel (comps.), Los Andes: cincuenta años después (1953-2003). Homenaje a John Murra, Lima, PUCP, 2003: 129-170.

Madariaga Varela, Raúl, «Presencia del vino en testamentos de indígenas», Palimpsesto, 6 (Santiago, diciembre de 2006): www.palimpsestousach.cl/numero6/int02.htm.

Mellafe, Rolando, «Esquema del fenómeno migratorio en el virreinato peruano», Rolando Mellafe (ed.), Historia social de Chile y América. Sugerencias y aproximaciones, Santiago, Editorial Universitaria, 1986: 131-145.

Mellafe, Rolando, «Alma y utopía: Santiago colonial», Cuadernos de historia, 15 (Santiago, 1995): 37-48.

Muñoz, Juan Guillermo, Pobladores de Chile, 1565-1580, Temuco, Universidad de la Frontera, 1989.

Murra, John, «El control vertical de un máximo de pisos ecológicos en la economía de las sociedades andinas» [1975], John Murra (comp.), El mundo andino. Población, medio ambiente y economía, Lima, IEP, 2002: 85-125.

Pärssinen, Martti, Tawantinsuyu. El Estado inca y su organización política, Lima, IFEA/PUCP, 2003.

Platt, Tristan, Bouysse-Cassagne, Thérèse y Harris, Olivia, Qaraqara-Charka-Mall$k u$, Inka y Rey en la provincia de Charcas (siglos XV-XVII). Historia antropológica de una confederación aymara, La Paz, IFEA / Plural / U. St. Andrews / U. London / Inter-American Foundation / Fundación Cultural del Banco Central de Bolivia, 2006.

Poloni Simard, Jacques, «Testamentos indígenas e indicadores de transformación de la sociedad indígena colonial (Cuenca, siglo XVII)», Thérèse Bouysse-Cassagne (ed.), Saberes y memorias en los Andes. In memoriam Thierry Saignes, ParisLima, CREDAL / IFEA, 1997b: 279-299.

Poloni Simard, Jacques, La mosaïque indienne. Mobilité, stratification sociale et métissage dans le corregimiento de Cuenca (Équateur) du XVIe au XVIIIe siècle, Paris, École des Hautes Études en Sciences Sociales, 2000.

Retamal Ávila, Julio, «La otra Inés de la Conquista», Boletín de historia y geografía, 12 (Santiago, 1996): 49-76.

Retamal Ávila, Julio (comp.), Testamentos de «indios» en Chile colonial: 1564-1801, Santiago, Universidad Andrés Bello / RIL, 2000.

Robinson, David J. (ed.), Migration in Colonial Spanish America, Cambridge (Mass.), Cambridge University Press, 1990.

Rodríguez Jiménez, Pablo, Testamentos indígenas de Santafé de Bogotá, siglos XVIXVII, Bogotá, Alcaldía Mayor de Bogotá, 2002. 
Ruiz Rodríguez, Carlos, La zona norte de Santiago: población, economía y urbanización, 1540-1833, tesis de Licenciatura en Historia, Santiago, Pontificia Universidad Católica de Chile, 1986.

Ruiz Rodríguez, Carlos, «Presencia de los mapuche-huilliche en Chile central en los siglos XVI-XVIII. Desarraigo y mestizaje», Boletín del Museo y Archivo Histórico Municipal de Osorno, 4 (Osorno, 1998): 1-71.

Ruiz Rodríguez, Carlos, «El mestizaje en Chile. Aspectos ideológicos», Historia de las mentalidades. Homenaje a Georges Duby, Santiago, Universidad de Chile, 2000: 245-267.

Ruiz Rodríguez, Carlos, «Mucho y muy buen vino. Producción vitivinícola en la zona norte de Santiago (siglos XVI-XVIII)», Revista de historia social y de las mentalidades, X/1 (Santiago, 2006): 55-92.

Sánchez Albornoz, Nicolás, La ciudad de Arequipa, 1573-1645. Condición, migración y trabajo indígenas, Arequipa, Universidad Nacional de San Agustín, 2003.

Silva, Osvaldo, «Consideraciones acerca del periodo Inca en la cuenca de Santiago (Chile Central)», Boletín del Museo Arqueológico de La Serena, 16 (La Serena, 1977-1978): 211-243.

Silva, Osvaldo, «Los promaucaes y la frontera meridional incaica en Chile», Cuadernos de historia, 6 (Santiago, 1986): 7-16.

Silva, Osvaldo, «Aproximaciones al estudio del mestizaje en Chile entre los siglos XVI y XVII», Sonia Pinto (ed.), Familia, matrimonio y mestizaje en Chile colonial, Santiago, Nuevo Mundo: cinco siglos, 1990: 13-34.

Stehberg, Rubén, «La fortaleza de Chena y su relación con la ocupación incaica de Chile», Boletín del Museo Nacional de Historia Natural, 23 (Santiago, 1976): 3-37.

Stehberg, Rubén y Sotomayor, Gonzalo, «La «estancia del gobernador» Pedro de Valdivia que fuera de los ingas passados y su relación con las cuencas de los ríos Aconcagua y Maipo-Mapocho» [manuscrito inédito].

Sternfeld, Gabriela, La organización laboral del Imperio Inca. Las autoridades locales básicas, Madrid/Frankfurt, Iberoamericana/Vervuert, 2007.

Thayer Ojeda, Tomás, Formación de la sociedad chilena y censo de la población de Chile en los años de 1540 a 1565, Santiago, Universidad de Chile, 1939, 3 vols.

Thayer Ojeda, Tomás, Santiago durante el siglo XVI. Constitución de la propiedad urbana i noticias biográficas de sus primeros pobladores, Santiago, Imprenta Cervantes, 1905.

Valdivia, Pedro de, Cartas de don _ que tratan del descubrimiento y conquista de la Nueva Extremadura, Santiago-Barcelona, Andrés Bello-Lumen, 1991. 
Valenzuela Márquez, Jaime, «Une société dépersonnalisée? Ordre colonial et référents identitaires à Santiago du Chili au XVII ${ }^{e}$ siècle», Bernard Lavallé (ed.), Transgressions et stratégies du métissage en Amérique coloniale, Paris, Presses de la Sorbonne Nouvelle, 1999: 139-163.

Valenzuela Márquez, Jaime, «Afán de prestigio y movilidad social: los espejos de la apariencia», Rafael Sagredo y Cristián Gazmuri (eds.), Historia de la vida privada en Chile, Santiago, Taurus, vol. I (2005): 71-93.

Valenzuela Márquez, Jaime, «Esclavos mapuches. Para una historia del secuestro y deportación de indígenas en la Colonia», Rafael Gaune y Martín Lara (coords.), Historias de racismo y discriminación en Chile, Santiago, UqBar, 2009: 225-260.

Valenzuela Márquez, Jaime, «Devociones de inmigrantes. Indígenas andinos y plurietnicidad urbana en la conformación de cofradías coloniales (Santiago de Chile, siglo XVII)», Historia, 43/I (Santiago, 2010a): 203-244.

Valenzuela Márquez, Jaime, «Inmigrantes en busca de identidad: los indios cuzcos de Santiago de Chile, entre clasificación colonial y estrategia social», Alejandra Araya y Jaime Valenzuela (eds.), América colonial. Denominaciones, clasificaciones e identidades, Santiago, Pontificia Universidad Católica de Chile / Universidad de Chile / RiL, 2010b: 79-118.

Vázquez de Espinosa, Antonio, Compendio y descripción de las indias occidentales [ca. 1629], Madrid, BAE, vol. 231, 1969.

Vieira Powers, Karen, Andean Journeys: Migration, Ethnogenesis, and the State in Colonial Quito, Albuquerque, University of New Mexico Press, 1995.

Villalobos, Sergio, Historia del pueblo chileno, Santiago, Zig-Zag, 1983, vols. I y II.

Wightman, Ann M., Indigenous Migration and Social Change. The Forasteros of Cuzco, 1570-1720, Durham/London, Duke University Press, 1990.

Zúñiga, Jean-Paul, Espagnols d'outre-mer. Émigration, métissage et reproduction sociale à Santiago du Chili, au 17e siècle, Paris, EHESS, 2002. 


\section{THE ANDEAN INDIGENOUS IN COLONIAL CHILE: IMMIGRATION, SPATIAL INSERTION, ECONOMIC INTEGRATION AND SOCIAL MOBILITY (SANTIAGO, 16TH-17TH CENTURIES)}

Beginning with the 16th century conquering expeditions, many Andean natives who served the Spaniards arrived in Chile, where they settled in and integrated in the work and social areas of this outlying "New World»; they formed local networks and relationships, had offspring; a number of them became artisans and some drafted wills or left their mark in ecclesiastical or notarized documents that provide us with an idea of their mobility and local integration. This work offers a background and reveals the principle hubs of a process resembling a medullar structure, in order to understand how the early Chilean colonial society was made up. At the same time, it provides insights into the phenomena of movement, uprooting and settlement of the indigenous population in the southern Peruvian viceroyalty.

KeY WORDS: Indigenous population, immigration, Chile, Peru, artisans, 16th century; 17th century. 